\title{
Anti-hemolytic and Anti-cytotoxic Effect of Two Artemisia Species (A. campestris and $A$. herba-alba) Essential Oil against Snake Venom
}

\author{
Ichrak Jaouadi $^{1 *}$, Zaineb Abdelkafi-Koubaa ${ }^{2}$, Sana Riabi-Ayari², Imed Hassen ${ }^{3}$, Mbarka Tej Yakoubi ${ }^{1}$, Mohamed El \\ Ayeb $^{2}$, Mohamed El Gazzah ${ }^{1}$ and Naziha Marrakchi ${ }^{\mathbf{2}, 4}$ \\ ${ }^{1}$ EL Manar University, Faculty of Sciences, Department of Biology, Tunis, Tunisia, 2092 \\ ${ }^{2}$ Institut Pasteur de Tunis, 13, Place Pasteur B.P.74 1002, Tunis, Belvédère, Tunisie \\ ${ }^{3}$ Research laboratory of methods and analyses technical (LMTA), Sidi Thabet Biotechnopole, 2020, Sidi Thabet, Tunisia \\ ${ }^{4}$ Faculty of medicine of Tunis, 1007 Tunis, Tunisia \\ *For correspondence: Ichrak.jaouadi@gmail.com
}

\begin{abstract}
In this study, we verify the possible activity of Artemisia herba-alba and A. campestris (Asteraceae) essential oil against the snake venoms. The leaves of $A$. campestris has been used in the folk medicine against snake moisture. The aerial part extracts of both plants have been tested for their action against snake venom. Interaction of $A$. campestris (E1) and A. herba alba (E2) essential oils with proteins extracted from snake venom has been tested. Lethality in mice, inflammation and cytotoxicity induced by Cerastes cerastes venoms were significantly inhibited by the mixture of different amounts of E1 and E2 and the venom. However, both extracts showed neutralization of the venoms hemolytic activity which is more important with E2. Chemical characterization of E1 and E2 revealed there is an important amount of polyphenols and tannins which are known by their bio-active effect. The result could lead as to think that these components have an action by inhibiting the toxicity of snake venoms in vitro. We can conclude therefore that the use of the essential oil from the two Artemisia species have a curative effect on the snake venom. These results confirmed the traditional use of $A$. campestris and we discovered a similar effect of $A$. herba-alba. No data have been reported till now about the essential oil curative effect of both species. (C) 2016 Friends Science Publishers
\end{abstract}

Keywords: Snake venom; Artemisia; Essential oils; cytotoxicity; lethality Abbreviation: BPB: Bromophenol blue; C. c: Cerastes cerastes venom; E1: Artemesia campestris essential oil; E2: Artemesia herba-alba essential oil; GC-MS: Gas chromatography-mass spectrometry; HMEC-1 cells: Human Microvascular Endothelial Cell; LD 50 : lethal dosage value; MiHD: The minimum indirect hemolytic dose; MTT: 3-(4,5-dimethylthiazol-2yl)-2,5-diphenyltetrazolium bromide; OPD: o-phenylenediamine; SDS: sodium dodecyl sulfate.

\section{Introduction}

The medicinal plant gained more importance as source of bioactive compounds to defeat many diseases. Some substances showed an antitumor effect like Artemisinin, an active constituent of Chinese wormwood (Artemisia absinthium) which is a potent antimalarial and recently research showed its antiangiogenic properties (Efferth et al., 2001; 2002). Methanol Stem Bark Extract of Brachystegia eurycoma possesses significant anti-inflammatory and analgesic properties (Igbe et al., 2012).

The phytotherapy offers an opportunity to reconsider the treatment of snake bites, especially in Africa. The cost relatively high of the antivenom serotherapy makes the recourse to this treatment not easy. In some places in the world different plant species were used in popular medicine for protection against snake bites (Mors et al., 2000).

The antiophidian effect of many medicinal plants has been used in the traditional medicine. However, just some species have been studied and still a lot of active compounds are not extracted and identified. In our study we have demonstrated the antivenom protection effect of the essential oils of two Tunisian plants Artemisia campestris and $A$. herba-alba. The first species have been used in the folk medicine to protect against snake bite in the semi arid and arid region of Tunisia. This is the first study testing the essential oil extract of the two species against the snake venom.

\section{Materials and Methods}

Physico-chemical Analysis of Essential Oil Extracts: Techniques and Analytics Methodology

Gas chromatography and retention indices: Due to their physico-chemical nature, the essential oil extracts (a mixture

To cite this paper: Jaouadi, I., Z. Abdelkafi-Koubaa, S. Riabi-Ayari, I. Hassen, M.T. Yakoubi, M. El-Ayeb, M. El-Gazzah and N. Marrakchi, 2016. Antihemolytic and anti-cytotoxic effect of two Artemisia species (A. campestris and A. herba-alba) essential oil against snake venom. Int. J. Agric. Biol., 18: 805-812 
of volatiles compounds) were adapted very well to an analysis by gas phase.

The gas chromatography (GC) is indeed a technique of separation of gaseous compounds which could be vaporized by heating without decomposition. The result of a GC analysis is recorded as a chromatogram representing a succession of peaks characterized by retention times and areas. These areas depend on the used detector and are generally proportional to the concentrations of the molecules forming the mixture initially injected.

GC identification of compounds is mainly due to their retention time. This approach faces a major limitation related to the fact that this quantity is directly dependent on the nature of the stationary phase used, but the experimental conditions (particularly temperature programming). To overcome these experimental conditions which vary from one analyst to another, and in order to obtain usable quantities as fixed references, it uses what is called "Kovats Indices (KI)" or "retention indices (RI)."

Retention indices (RI) is calculated using as a reference the retention time of a reference range of linear alkanes (n-alkanes) using the following formula:

- $\mathrm{n}, \mathrm{n}+1$ : carbon atoms number of the reference compounds - $\mathrm{R}(\mathrm{x})$ : retention time of the compound to be analyzed

- $T^{\prime} R(n)$ : reference compound retention times which elutes before $\mathrm{X}$

- $\mathrm{R}(\mathrm{n}+1)$ : reference compound retention times which elutes after $\mathrm{X}$

- $\mathrm{Cn}$ : carbon number in the series of n-alkanes (example: $\mathrm{Cn}$ $=8$ octane $(\mathrm{C} 8$ noted $), \mathrm{Cn}=9$ nonane $(\mathrm{C} 9$ noted $)$

$$
I R=100 * C_{n}+100 .\left(C_{n+i}-C_{n}\right) \frac{t_{R(x)}-\operatorname{tR}(n)}{\operatorname{tR}(n+i)-t_{R(n)}}
$$

Note that if the oven programming is isothermal (constant temperature), it is called "Kovats indices" (IK), whereas if operating with a temperature program (temperature gradient), then it is in this case of "retention index" (IR). In both cases, the calculated ratios are then compared with those for the reference product (measured in the laboratory or described in the literature). Note that it is common to observe changes, sometimes significant, when comparing retention indices obtained in the laboratory and those in the literature (in particular polar column) (Adams, 2007).

\section{Contribution of Mass Spectrometry}

Given the very large number of compounds commonly found in samples of essential oils (which can lead to coelution and therefore identical retention indices), this identification criteria must be complemented by other analytical data, such as those provided by the coupling between the GC and mass spectrometry.

The GC-MS [gas chromatography (GC) with mass spectrometry (MS)] gives indeed a very important possibility of identification of volatile compounds from a mixture. A mass detector placed at the column outlet allows the production of mass spectra for each of the eluted components. These spectra are then compared with those of the reference products in commercial computerized library containing several thousands of spectra (McLafferty, 1989).

Both identification criteria proposed (namely "the mass spectrum" in addition to "confirmation with the retention indices") are generally sufficient to ensure with a great probability the identity of the test compound. However, the current accredited laboratories requires the use of two retention indices for each compound, calculated respectively at two different stationary phases (polar and apolar). Unfortunately, this recommendation has not been followed as part of this work, availability of polar column fault.

\section{Operating Conditions}

Analyses were performed using an Agilent brand chromatograph $(6890 \mathrm{~N}$ model) equipped with an auto sampler (Agilent 7683B and coupled to a mass detector (Agilent 5973 MSD). The data were treated at the Using the software "ChemStation" and "Nist Search", armed with mass spectral libraries other experimental conditions are described in the following:

Capillary column HP-5MS $(30 \mathrm{~m} * 0.25 \mathrm{~mm} * 0.25 \mu \mathrm{m})$ (column length * inside diameter * film thickness of the stationary phase).

$\square$ Injection method: Injection with division (split) in a ratio of 1: 200 . The temperature of the injector was set at $250^{\circ} \mathrm{C}$ and the volume injected is $0.2 \mu \mathrm{L}$.

Program temperature: Initial temperature set at $40^{\circ} \mathrm{C}$ (hold for $1 \mathrm{~min}$ ) and the temperature rise to $300^{\circ} \mathrm{C}$ with a level of $4^{\circ} \mathrm{C} / \mathrm{min}$. The final temperature $\left(300^{\circ} \mathrm{C}\right)$ is finally held for $10 \mathrm{~min}$. The total time of the analysis is $76 \mathrm{~min}$.

The composition of $A$. campestris $\mathrm{E} 1$ is depicted in Table 1 while that of A. herba-alba E2 is given in Table 2.

\section{Venom collection}

The Venom collection is realized from two species of snake: Cerastes cerastes and Macrovipera lebetina at the Pasteur Institute's serpentarium (Tunis, Tunisia) then stored at $20^{\circ} \mathrm{C}$. Human fibrinogen and Rat type IV Collagen were purchased from Sigma Chemical (St. Louis, USA). Cell culture supplements and chemical product were obtained from GIBCO (Cergy-Pontoise, France).

\section{Essential oil Extracts and Proteins Association}

To verify the association between the extracts and proteins, SDS-PAGE at $12 \%$ was performed according to Laemmli (Laemmli, 1970) with $50.0 \mu \mathrm{g}$ of $C$. cerastes venom $(C . c)$ and mixed with $1000 \mu \mathrm{g}$ of each extract E1 (A. campestris essential oil) E2 (A. herba-alba essential oil). 
Plant Extracts Effect on Snake Venom Lethality / Int. J. Agric. Biol., Vol. 18, No. 4, 2016

Table 1: Chemical composition (\%) of A. campestris essential oil

\begin{tabular}{|c|c|c|c|c|c|c|}
\hline $\mathrm{N}^{\circ}$ & RT (min.) & Compounds & CAS & $\mathrm{IR}_{\text {Lit }}$ & $\mathrm{IR}_{\mathrm{cal}}$ & $\%$ Total peak area \\
\hline 1 & 9,05 & $\alpha$-Thujene & $2867-05-2$ & 925 & 917 & 0,32 \\
\hline 2 & 9,30 & $\alpha$-Pinene & $80-56-8$ & 931 & 925 & 11,83 \\
\hline 3 & 9,77 & Camphene & $79-92-5$ & 949 & 939 & 0,17 \\
\hline 4 & 9,97 & Verbenene & $36262-09-6$ & 951 & 946 & 0,06 \\
\hline 5 & 10,85 & $\beta$-Pinene & $127-91-3$ & 965 & 973 & 33,7 \\
\hline 6 & 11,34 & $\beta$-Myrcene & $123-35-3$ & 992 & 988 & 4,35 \\
\hline 7 & 11,49 & Cyclooctene oxide & $286-62-4$ & - & 993 & 0,14 \\
\hline 8 & 11,77 & $\alpha$-Phellandrene & $99-83-2$ & 1003 & 1002 & 0,07 \\
\hline 9 & 12,22 & $\alpha$-Terpinene & $99-86-5$ & 1019 & 1014 & 0,67 \\
\hline 10 & 12,55 & $O$-Cymene & $527-84-4$ & 1022 & 1023 & 6,73 \\
\hline 11 & 12,71 & Limonene & $138-86-3$ & 1033 & 1028 & 10,19 \\
\hline 12 & 13,03 & $\beta$-cis-Ocimene & $3338-55-4$ & 1037 & 1036 & 0,87 \\
\hline 13 & 13,41 & $\beta$-trans-Ocimene & $3779-61-1$ & 1045 & 1047 & 1,21 \\
\hline 14 & 13,80 & $\gamma$-Terpinene & $99-85-4$ & 1061 & 1057 & 3,18 \\
\hline 15 & 14,85 & Terpinolene & $586-62-9$ & 1086 & 1086 & 0,57 \\
\hline 16 & 15,31 & $\beta$-Linalool & $78-70-6$ & 1097 & 1099 & 0,42 \\
\hline 17 & 15,50 & $\beta$-Thujone & $471-15-8$ & 1116 & 1104 & 0,51 \\
\hline 18 & 15,79 & Fenchol & $1632-73-1$ & 1111 & 1112 & 0,07 \\
\hline 19 & 15,90 & $\alpha$-Thujone & $546-80-5$ & 1112 & 1115 & 0,22 \\
\hline 20 & 16,07 & Trans-2-menthenol & $29803-81-4$ & 1120 & 1120 & 0,23 \\
\hline 21 & 16,25 & $\alpha$-Campholenal & $4501-58-0$ & 1127 & 1125 & 0,18 \\
\hline 22 & 16,70 & Trans-pinocarveol & $547-61-5$ & 1140 & 1137 & 0,85 \\
\hline 23 & 16,90 & Camphor & $464-48-2$ & 1139 & 1143 & 0,3 \\
\hline 24 & 17,08 & 2,6-nonadienol & $28069-72-9$ & 1160 & 1147 & 0,2 \\
\hline 25 & 17,56 & Pinocarvone & $30460-92-5$ & 1168 & 1161 & 0,38 \\
\hline 26 & 17,71 & Borneol & $507-70-0$ & 1165 & 1165 & 0,07 \\
\hline 27 & 17,75 & $\alpha$-Phellandren-8-ol & $1686-20-0$ & 1165 & 1166 & 0,12 \\
\hline 28 & 17,98 & Umbellulone & 24545-81-1 & 1170 & 1172 & 0,07 \\
\hline 29 & 18,13 & (-)-Terpinen-4-ol & $20126-76-5$ & 1181 & 1176 & 3,23 \\
\hline 30 & 18,43 & Crypton & $500-02-7$ & 1186 & 1185 & 0,33 \\
\hline 31 & 18,60 & $\alpha$-Terpineol & $98-55-5$ & 1196 & 1189 & 1,09 \\
\hline 32 & 18,80 & Myrtenal & $564-94-3$ & 1194 & 1195 & 0,82 \\
\hline 33 & 19,20 & Trans-piperitol & $16721-39-4$ & 1205 & 1206 & 0,15 \\
\hline 34 & 19,60 & Cis-carveol & $1197-06-4$ & 1225 & 1218 & 0,17 \\
\hline 35 & 20,16 & Cis-3-hexenyl isovalerate & $35154-45-1$ & 1238 & 1235 & 0,41 \\
\hline 36 & 20,35 & $\mathrm{~N}$-hexyl iso-valerate & $10032-13-0$ & 1242 & 1240 & 0,19 \\
\hline 37 & 20,45 & Carvone & $99-49-0$ & 1244 & 1243 & 0,18 \\
\hline 38 & 20,83 & Geranyl vinyl ether & - & 1250 & 1254 & 0,31 \\
\hline 39 & 21,53 & Phellandral & 21391-98-0 & 1276 & 1275 & 0,11 \\
\hline 40 & 24,89 & $\alpha$-Ylangene & $14912-44-8$ & 1374 & 1375 & 0,13 \\
\hline 41 & 25,10 & Geraniol acetate & $105-87-3$ & 1380 & 1381 & 1,54 \\
\hline 42 & 26,30 & Caryophyllene & $87-44-5$ & 1422 & 1419 & 0,11 \\
\hline 43 & 27,36 & $\alpha$-Caryophyllene & $6753-98-6$ & 1453 & 1454 & 0,09 \\
\hline 44 & 28,06 & $\gamma$-Muurolene & $30021-74-0$ & 1477 & 1477 & 0,25 \\
\hline 45 & 28,21 & Germacrene D & $23986-74-5$ & 1484 & 1482 & 0,94 \\
\hline 46 & 28,68 & Germacrene B & $15423-57-1$ & 1494 & 1497 & 0,14 \\
\hline 47 & 28,78 & $\alpha$-Muurolene & $31983-22-9$ & 1499 & 1501 & 0,12 \\
\hline 48 & 28,98 & $\alpha$-Farnesene & $502-61-4$ & 1505 & 1507 & 0,17 \\
\hline 49 & 29,20 & $\gamma$-Cadinene & $39029-41-9$ & 1513 & 1515 & 0,14 \\
\hline 50 & 29,47 & $\delta$-Cadinene & $483-76-1$ & 1524 & 1524 & 0,48 \\
\hline 51 & 30,63 & Nerodlidol & $7212-44-4$ & 1561 & 1562 & 0,24 \\
\hline 52 & 31,12 & Spathulenol & $6750-60-3$ & 1585 & 1578 & 2,14 \\
\hline 53 & 31,28 & Caryophyllene oxide & $1139-30-6$ & 1583 & 1583 & 0,35 \\
\hline 54 & 31,42 & $\beta$-Cedren-9- $\alpha$-ol & - & 1586 & 1588 & 0,08 \\
\hline 55 & 31,91 & Geranyl isovalerate & $109-20-6$ & 1613 & 1604 & 1,77 \\
\hline 56 & 32,29 & $\tau$-Cadinaol & $5937-11-1$ & 1618 & 1619 & 0,09 \\
\hline 57 & 32,59 & $\gamma$-Eudesmol & $1209-71-8$ & 1631 & 1630 & 0,42 \\
\hline 58 & 32,94 & $\tau$-Muurolol & $19912-62-0$ & 1648 & 1642 & 0,55 \\
\hline 59 & 33,21 & $\beta$-Eudesmol & $473-15-4$ & 1651 & 1652 & 2,96 \\
\hline 60 & 33,28 & $\alpha$-Cadinol & $481-34-5$ & 1663 & 1655 & 0,47 \\
\hline 61 & 34,17 & Eudesma-4,11-dien-2-ol & - & 1691 & 1687 & 0,27 \\
\hline
\end{tabular}


Table 2: Chemical composition (\%) of A. herba-alba essential oil

\begin{tabular}{|c|c|c|c|c|c|c|}
\hline $\mathrm{N}^{\circ}$ & RT (min.) & Compounds & CAS & $\mathrm{IR}_{\mathrm{Lit}}$ & $I_{\mathrm{cal}}$ & $\%$ Total peak area \\
\hline$\overline{1}$ & 9,04 & $\alpha$-Pinene & $80-56-8$ & 931 & 917 & 0,03 \\
\hline 2 & 9,77 & Camphene & $79-92-5$ & 949 & 940 & 0,78 \\
\hline 3 & 10,66 & Sabinene & $3387-41-5$ & 972 & 968 & 0,24 \\
\hline 4 & 10,76 & $\beta$-Pinene & $127-91-3$ & 972 & 971 & 0,08 \\
\hline 5 & 12,54 & $O$-cymene & $527-84-4$ & 1022 & 1023 & 0,55 \\
\hline 6 & 12,80 & Cineole & $470-82-6$ & 1030 & 1031 & 3,73 \\
\hline 7 & 15,82 & Thujone & $546-80-5$ & 1112 & 1113 & 22,88 \\
\hline 8 & 16,16 & Chrysanthone & $1125-12-8$ & 1124 & 1123 & 8,15 \\
\hline 9 & 16,39 & Chrysanthenone & $473-06-3$ & 1123 & 1129 & 2,59 \\
\hline 10 & 17,12 & Cis-sabinol & $471-16-9$ & 1140 & 1149 & 8,90 \\
\hline 11 & 17,20 & Camphor & $76-22-2$ & 1146 & 1151 & 6,02 \\
\hline 12 & 17,50 & Sabina ketone & $513-20-2$ & 1158 & 1159 & 0,17 \\
\hline 13 & 17,67 & Pinocarvone & $30460-92-5$ & 1168 & 1164 & 0,67 \\
\hline 14 & 17,84 & Borneol & $507-70-0$ & 1165 & 1169 & 1,81 \\
\hline 15 & 18,20 & (-)-Terpinen-4-ol & $20126-76-5$ & 1181 & 1179 & 0,59 \\
\hline 16 & 18,42 & $\alpha$-Thujenal & ? & 1182 & 1185 & 0,13 \\
\hline 17 & 18,65 & $\alpha$-Terpineol & $98-55-5$ & 1196 & 1191 & 0,14 \\
\hline 18 & 18,82 & Cis-piperitol & $16721-38-3$ & 1199 & 1196 & 0,31 \\
\hline 19 & 19,26 & Trans-piperitol & $16721-39-4$ & 1205 & 1208 & 0,49 \\
\hline 20 & 20,35 & Cumaldehyde & $122-03-2$ & 1236 & 1241 & 0,21 \\
\hline 21 & 20,49 & Carvone & $99-49-0$ & 1244 & 1245 & 0,10 \\
\hline 22 & 20,86 & Piperitone & $89-81-6$ & 1258 & 1256 & 0,33 \\
\hline 23 & 21,92 & L-Bornyl acetate & $5655-61-8$ & 1284 & 1287 & 0,14 \\
\hline 24 & 22,48 & Myrtenyl acetate & 1079-01-2 & 1306 & 1304 & 35,53 \\
\hline 25 & 22,58 & Carvacrol & $499-75-2$ & 1311 & 1307 & 0,14 \\
\hline 26 & 23,16 & 2,6-dimethyl-3,5-Heptadien-2-ol & $77411-76-8$ & ? & 1324 & 0,14 \\
\hline 27 & 25,67 & Jasmone & $488-10-8$ & 1393 & 1398 & 0,37 \\
\hline 28 & 28,24 & Germacrene D & $23986-74-5$ & 1484 & 1483 & 0,09 \\
\hline 29 & 28,71 & Bicyclogermacrene & $67650-90-2$ & 1495 & 1499 & 0,07 \\
\hline 30 & 29,16 & Davana ether & $35470-57-6$ & 1491 & 1514 & 0,19 \\
\hline 31 & 31,15 & Spathulenol & $6750-60-3$ & 1585 & 1579 & 0,58 \\
\hline 32 & 31,30 & Caryophyllene oxide & $1139-30-6$ & 1583 & 1584 & 0,11 \\
\hline 33 & 32,22 & Vinyl cyclohexanecarboxylate & $4840-76-0$ & $?$ & 1616 & 0,17 \\
\hline 34 & 34,06 & Cis-6-dodecen-4-olide & $18679-18-0$ & 1675 & 1684 & 0,10 \\
\hline
\end{tabular}

In Vitro Determination of Essential oil Effect on Fibrinogen Hydrolytic Activity

Extracts E1 and E2 were added separately to a solution of $0.1 \%$ human fibrinogen mixed with $50 \mathrm{mM}$ of Tris-HCl buffer (at $\mathrm{pH}$ 7.5) (a volume of $1 \mathrm{~mL}$ ) and a venom solution concentration of $(20 \mu \mathrm{g})$ we used as reference the method of Ouyang and Teng (1976). The mixture was incubated in the presence at first and then in absence of extracts $(1 \mathrm{mg})$ at $37^{\circ} \mathrm{C} .100 \mu \mathrm{L}$ of denaturing solution aliquots was added $(10$ $\mathrm{mM}$ phosphate buffer, $\mathrm{pH} 7.2$, containing $10 \mathrm{M}$ urea, $4 \%$ sodium dodecyl sulfate (SDS), and $4 \% \beta$-mercaptoethanol) at various time intervals. Then the solution was incubated at $37^{\circ} \mathrm{C}$ for $6 \mathrm{~h}$ and run on $10 \%$ polyacrylamide slab gel electrophoresis which was carried out for $2 \mathrm{~h}$ with a current of $25 \mathrm{~mA}$ per slab gel. The Bromophenol blue (BPB) solution was used as an indicator.

\section{In Vitro Determination of the Essential Oils Effect on Caseinolytic Activity}

We used a modified protocol of Rodrigues et al. (2000). In this method we choose casein as substrate with $40 \mu \mathrm{g}$ of $C$. cerastes crude venom. The same assay was carried out adding the essential oils E1 and E2 separately after pre- incubation for $30 \mathrm{~min}$ at $37^{\circ} \mathrm{C}$ with different venom concentrations $(\mathrm{w} / \mathrm{w})$. To define one unit of caseinolytic activity we consider the increase in absorbance of 0.001 $\mathrm{U} / \mathrm{min}$ produced by the amount of venom/protease.

\section{In Vitro Determination of the Essential Oils Effect on Collagen Hydrolytic Activity}

The test was realized using the following method: Sodium hydrogen carbonate solution $(60 \mu \mathrm{L}, \mathrm{pH} 12)$ was added to $0.3 \%$ type IV collagen $(0.9 \mathrm{~mL})$ and adjusted to $\mathrm{pH}$ 8. $20 \mu \mathrm{g}$ of $C$. cerastes were incubated with type IV collagen aliquots in the presence at first then in absence of Extracts E1 and E2 $(1 \mathrm{mg})$. Aliquots of $100 \mu \mathrm{L}$ of

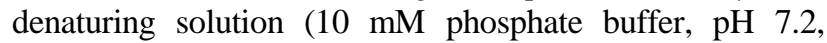
containing $10 \mathrm{M}$ urea, $4 \%$ SDS, and $4 \% \beta$-mercaptoethanol) were added during various interval time. This solution was boiled for $3 \mathrm{~min}$ and run on SDS-PAGE using a 7.5\% polyacrylamide slab gel electrophoresis.

\section{In Vitro Determination of Essential Oils Effect on L- Amino Acid Oxidase Activity}

We used Kishimoto and Takahashi (2001) method. $C$. cerastes venom or LAAO was pre-incubated with extracts 
for $30 \mathrm{~min}$ at $37^{\circ} \mathrm{C}$ for the inhibition test.

\section{Essential Oils Effect on Phospholipase Activity A2}

$\mathrm{A}_{2}$ activity was measured based on its indirect hemolytic action on agarose gel, using egg yolk and red blood cells as substrate. The minimum indirect hemolytic dose (MiHD) was defined as being the amount of venom that could produce a $10 \mathrm{~mm}$ diameter of hemolytic halo. To evaluate the ability of Extracts to inhibit phospholipase activity we pre-incubated each extract E1 and E2 with MiHD of $C$. cerastes or M. lebetina venoms (1:10 w/w). Control samples contained venom without Plant extracts. Plates were incubated at $37^{\circ} \mathrm{C}$ overnight. The efficacy of the two species essential oils in neutralizing the phospholipase activity was expressed as $100 \%$ inhibition corresponding to the absence of a hemolytic halo. Each assay was performed in triplicate and expressed as mean \pm standard deviation of the mean.

\section{Essential Oils Effect on Venom Cytotoxicity on HMEC}

Cell culture: HMEC-1 cells have been cultivated according to Bourdron et al. (2006).

\section{Essential Oils Effect on Venom Cytotoxic Action}

Cerastes cerastes venom on HMEC-1 cells was investigated. The cells were trypsinized at first then washed with the same medium and re-suspended in the growth media. These cells were seeded in 96-multiwell plates $\left(5 \times 10^{3}\right.$ cells per well in $100 \mu \mathrm{L}$ medium) till they attach and reach log phase of growth. Various concentrations of essential oils E1 and E2 ( $\mu \mathrm{g} / \mathrm{mL}$ in 10\% DMSO-saline) in the presence or absence of $C$. cerastes venom were added to each well in $100 \mu \mathrm{L}$ medium. Cell viability was tested by MTT (3-(4,5-dimethylthiazol-2-yl)-2,5-diphenyltetrazolium bromide) according to Mosmann (1983) protocol. We used spectra Max microplate reader (Thermo scientific, USA) for the absorbance at $550 \mathrm{~nm}$.

\section{In Vivo Test}

Acute toxicity of the extracts and venom: The venom lethality was tested by subcutaneous routes in albino mice (18-22 g). Various concentrations of $C$. cerastes and $M$. lebetina venoms solution (venom dissolved in saline solution) were used $(1.0-10 \mathrm{mg} / \mathrm{mL})$. We have injected 100 $\mu \mathrm{L}$ of each solution. For control mice received saline solution without adding venom. Deaths were recorded during $48 \mathrm{~h}$ and $\mathrm{LD}_{50}$ was calculated by probits.

The effect of extracts on the neutralization of toxicity of snake venom was determined by mixing each extract with snake venom $\left(2 \mathrm{LD}_{50}\right)$ before injection. Deaths were registered within $24 \mathrm{~h}$ and results were the mean.
Edema-inducing activity: Intradermal injection of $20 \mu \mathrm{g}$ from $C$. cerastes venom was realized in the right foot pad of male albino mice (weight: $18-22 \mathrm{~g}$ ) to induce edema. To verify the essential oil inhibition action on venom, we incubated the venom with different concentration of $\mathrm{E} 1$ and E2 (w/w) separately. $50 \mu \mathrm{L}$ of phosphate-buffered saline (PBS, pH7.2), DMSO or plant extracts were injected to the control groups. To determine the edema progression a low pressure pachymeter (Mitutoyo, Japan) have been used after $24 \mathrm{~h}$.

\section{Results}

\section{Essential Oil Composition}

The major compounds of the A. campestris essential oil were the $\beta$-pinene $(33.7 \%)$ followed by the $\alpha$-pinene and Limonene $(11.83 \%, 10.19 \%)$ (Table 1). For A. herba-alba essential oil the major compounds were Myrtenyl acetate $(35.53 \%)$ followed by thujone $(22.88 \%)$ (Table 3$)$.

\section{In Vitro Test}

Interaction between snake venoms and essential oils (SDS-PAGE): We have noted absence of visible change in the electrophoretic pattern of $C$. cerastes venom, during its incubation with extracts (Fig. 1). This is eliminating the hypothesis of the protein degradation as a possible reaction. Furthermore, no proteins in the extracts were detected.

Fibrinogen hydrolytic activity assay: The human fibrinogen incubation with $C$. cerastes venom $(C . \quad c)$ revealed that the $A \alpha$ band of the fibrinogen disappeared on SDS-PAGE, whereas the $\beta$ chain and $\gamma$ chain were unaffected (Fig. 2a). The mixture of venom and plant extracts (E1 and E2) did not show a significant protection of the degradation of human fibrinogen (Fig. 2b and c).

Collagen hydrolytic activity assay: Type IV collagen was incubated with $C$. cerastes venom at different periods of time. The venom degraded completely type IV collagen (104 kDa), especially over $1 \mathrm{~h}$, to smaller molecular weights (43 and $35 \mathrm{kDa}$ )(data not shown). In the presence of extracts $(0.5 \mathrm{mg} / \mathrm{mL})$, type IV collagen was digested by incubation with the venom (data not shown).

Proteolytic activity on casein: The E1 showed more important caseinolytic hydrolytic activity inhibition beginning with the ratio of 1:10 (Fig. 3a), while the E2 has less inhibition effect for the same rate (Fig. 3b).

LAAO activity assay: The LAAO activity test showed no significant decrease of the enzymatic activity of crude venom with the presence of E1 or E2 (Fig. 4a). Furthermore, purified L-amino acid oxidase of $C$. cerastes venom was not inhibited by any of the extracts (E1 and E2) (Fig. 4b). 
Table 3: Neutralization of the indirect hemolytic activity of C. cerastes and M. lebetina venoms by extracts of plants

\begin{tabular}{lll}
\hline Venom & Plant extract & \% of inhibition \\
\hline CC & E1 & $31 \% \pm 5$ \\
& E2 & $49 \% \pm 3$ \\
MVL & E1 & $27 \% \pm 2$ \\
& E2 & $34 \% \pm 3$ \\
\hline
\end{tabular}

Both extracts were tested against one minimum indirect hemolytic dose (MiHD) $(5 \mu \mathrm{g})$ of CC or MVL venoms, in agarose-erythrocyte-egg yolk gels. Experiments performed by triplicate

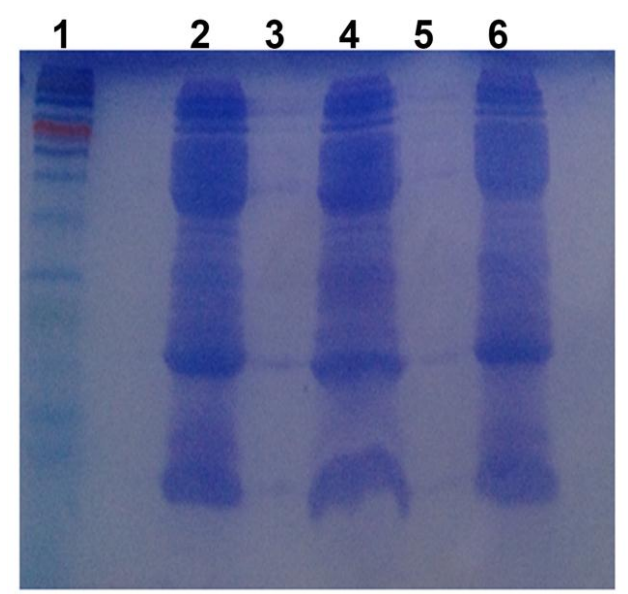

Fig. 1: Electrophoretic analysis of the interaction between venom and extracts on SDS-PAGE. Lane 1molecular mass markers; lane 2- C. cerastes crude venom; lane 3-E1, lane 4- E1 and crude venom, lane 5E2 and lane 6- E2 and crude venom

Indirect haemolytic assay: The two extracts demonstrated neutralizing activity against C.C and MVL venom which is more significant with E2 (Table 3).

\section{Inhibition of Venom Cytotoxic Action on HMEC}

E1 or E2 alone had no effect on the viability of HMEC. The cell viability is more important when the $\mathrm{E} 1$ and $\mathrm{E} 2$ were added and it significantly protected HMEC against cytotoxic effects of C.C venom at all concentrations of the tested extracts. The maximum (99\%) protective effect was exhibited with E1 at $2.5 \mu \mathrm{M}$ (Fig. 5a) than E2 with 95\% (Fig. 5b). The anti-venom effect is much higher for E1 than E2 after incubation and it is similar for both extract without prior incubation (Fig. 5c).

\section{In Vivo Tests}

Essential oils neutralization effect on venom lethality: Subcutaneous viper venom $\left(2 \mathrm{LD}_{50}\right)$ has been injected into male albino mice than an injection of E1 and E2 has been injected later (1 mg per mouse PO). The C.C and $V L$ venom lethality has been remarquebly stopped by E1 and E2. The first extract added to the C.C venom showed one survival

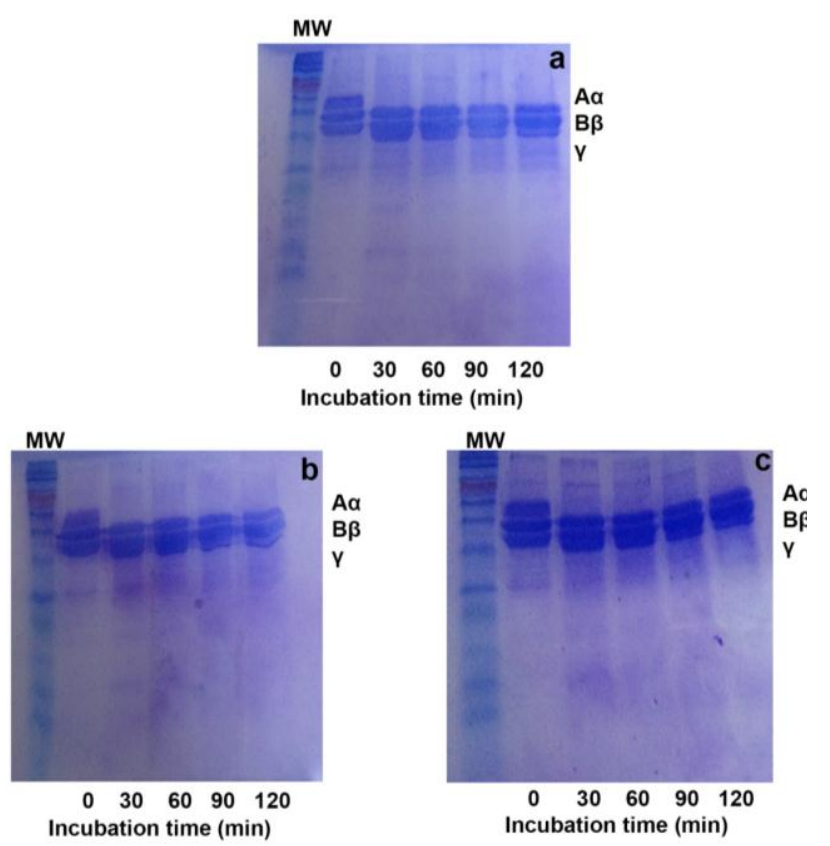

Fig. 2: Effects of Extracts on human fibrinogen hydrolytic activities by $C$. cerastes venom. $10 \%$ SDS-PAGE of timedependent digestion of human fibrinogen by $C$. cerastes venom in the presence or absence of Extracts. (a) $C$. cerastes venom without Extracts; (b) C. cerastes venom with E1; (c) C. cerastes venom with E2
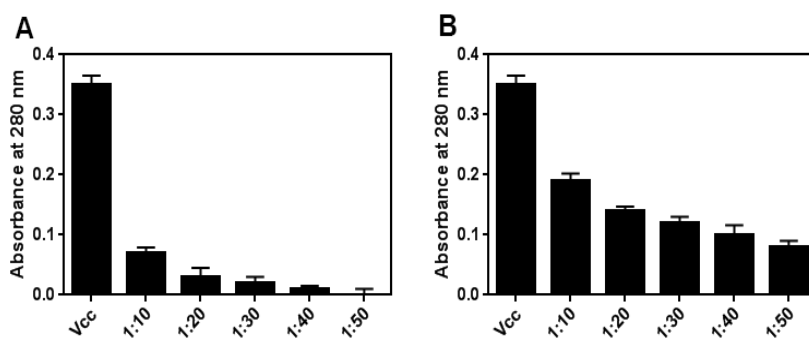

Fig. 3: Effects of Extracts on proteolytic activity on casein. (a) C. cerastes venom with E1; (b) C. cerastes venom with E2

mouse and the second extract 3 survival while the effect of the two extracts added to VL is less curative since for the first extract all mice were dead and for the second extract just one mouse survived.

Anti-inflammatory activity: The injection of $0.01 \mathrm{~mL}$ venom was followed by a remarquebale inflammation reaction in mice paw (at $1 \mathrm{~h}$ ), while the Pre-treatment with $E 1$ and $E 2$ (1 mg each) per mouse, PO before the injection of $C . C$ venom reduces this reaction. The minimization of oedema reaction was found to be almost similar for both extracts. In our study we realized that the essential oils E1 and E2 neutralized significantly the inflammation effect of the venom and therefore the oedema (Fig. 6). 
A

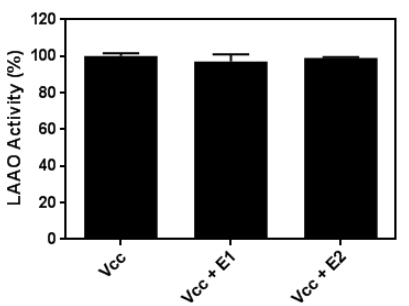

Fig. 4: Effects of Extracts on LAAO activity. (a) $C$. cerastes venom with Extracts; (b) Purified LAAO with Extracts

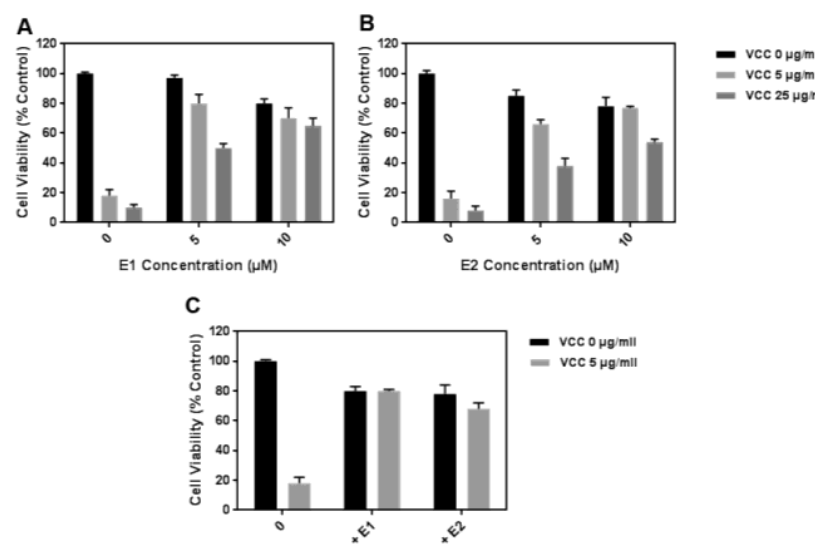

Fig. 5: Effect of Extracts against the cytotoxic actions of $C$. cerastes venom on HMEC. (a) Effect of E1, (b) Effect of E2, (c) Effect of Extracts against the cytotoxic actions of $C$. cerastes venom on HMEC without pre-incubation
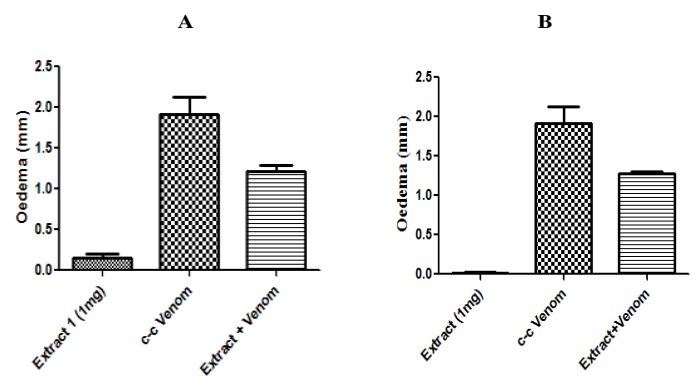

Extract (1mg) c-c Venom Extract+veno

Fig. 6: Anti-inflammatory activity of extracts

\section{Discussion}

The envenomation by snakes causes generally local tissue damage, consisting of oedema, haemorrhage, myonecrosis, haemolyse and inflammation. Many plant families have been used in traditional medicine as anti ophidian by treating damage caused by the snake venom (Andreimar $e t$ $a l ., 2005)$. Studies focused in some species to investigate and isolate the bioactive compounds from different part of the plant. The extracts from different parts of the plants belonging to the Asteraceae family showed an anti-

hemorrhagic, antiproteolytic, anti-phospholipase (Abid et al, 2007; Mariane et al, 2011), antilethality (Shirwaikar et al., 2004; Pithayanukul et al., 2009), antiedema, (Ticli et al., 2005; Nishijima et al., 2009), antinecrosis (Bjarnason et al., 1978; Houghton et al., 1992; Chareanchai et al., 2009; Soares et al., 2005), anti-myotoxicity (Theakston and Reid, 1992; Bjarnason and Fox, 1994; Soares et al., 2004) and anticoagulant effect (Bjarnason and Tu, 1978; Bjarnason and Fox, 1994). Our results have some similarities with those research investigations. The use of the Artemisia essential oils extract reduced the lethal effect on the mice. The extract has a neutralizing capacity against C.C venom. The same effect has been noticed with 74 ethanolic extracts of plants used in the folk medicine in Colombia (Otero et al., 2000). The essential oils of the two Artemisia species were composed of an important amount of phenolic compounds. It has been demonstrated that many phenolic compounds have an antivenom action such ar-turmerone extracted from Curcuma longa roots, the compound have been shown to neutralize the hemorrhagic and lethal effect induced by some venoms (Dob and Benabdelkader, 2006), tannic acid has an hemorrhagic neutralization effect (Maugini, 1930), 2-hydroxy-4-methoxy benzoic acid isolated from the methanolic root extract of Hemidesmus indicus neutralyzed inflammation (Ipshita and Chakravarty, 2006). According to Sanchez and Rodríguez (2008) the polyphenols can bind proteins and make the venom unable to act on receptors and act by competitive blocking of the receptors. These tests can explain the neutralized effect of $A$. campestris and $A$. herba-alba essential oils against the venom. Both species showed a decrease of the lethality effect of C.C venom and its cytotoxicity on HMEC. It has been shown that the two essential oils have an antihaemolytic effect like the most of the Asteraceae species extracts. The anti-venom actions are positive when the venom is mixed with the essential oils before the biological tests.

In this study we confirmed the biological anti-venom effect of $A$. campestris already used in the traditional medicine and we demonstrated a similar effect of $A$. herbaalba. Further studies will be performed to identify and isolate the pure compounds responsible for the venom inhibition from the two essential oils.

\section{References}

Abid, Z.B., M. Feki, A. Hédhili and M.H. Hamdaoui, 2007. Artemisia herba-alba Asso (Asteraceae) has equivalent effects to green and black tea decoctions on antioxidant processes and some metabolic parameters in rats. Ann. Nutr. Metab., 51: 216-222

Adams, R.P., 2007. Identification Of Essential Oil Components By Gas Chromatography/Mass Spectrometry, p: 804. Allured Publishing Corporation, Carol Stream, Illinois, USA

Bjarnason, J.B. and J.W. Fox, 1994. Hemorrhagic metalloproteinases from snake venoms. Pharmacol. Ther., 62: 325-372

Bjarnason, J.B. and A.T. Tu, 1978. Hemorrhagic toxins from western diamondback rattlesnake (Crotalus atrox) venom: Isolation and characterization of five toxins and the role of zinc in hemorrhagic toxine. Biochemistry, 17: 3395-3404 
Bourdron, J., L. Commeiras, P. Barbier, V. Bourgarel-Rey, E. Pasquier, N. Vanthuyne, J.C. Hubaud, V. Peyrot and J.L. Parrain, 2006. Caulerpenyne-colchicine hybrid: Synthesis and biological evaluation. Biol. Med. Chem., 14: 5540-5548

Chareanchai, J.L., P. Pithayanukul and R. Bavovada, 2009. Anti-necrosis potential of polyphenols against snake venoms. Immunopharmacol. Immunotoxicol., 31: 556-562

Dob, T. and T. Benabdelkader, 2006. Chemical composition of the essential oil of Artemisia herba-alba Assogrown in Algeria. J. Essen. Oil Res., 18: 685-690

Efferth, T., M. Davey, A. Olbrich, G. Rucker, E. Gebhart and R. Davey, 2002. Activity of drugs from traditional Chinese medicine toward sensitive and MDR1- or MRP1-overexpressing multidrugresistant human CCRF-CEM leukemia cells. Blood Cells Mol. Dis., 28: $160-168$

Efferth, T., H. Dunstan, A. Sauerbrey, H. Miyachi and C.R. Chitambar, 2001. The anti-malarial artesunate is also active against cancer. Int. J. Oncol., 18: 767-773

Houghton, P.J., I.M. Osbibogun and S. Bansal, 1992. A peptide from Schumanniophyton magnificum with anti-cobra venom activity. Planta Med., 58: 263-265

Igbe, I., B.A. Ayinde and A. Izuchukwu, 2012. Anti-inflammatory and Analgesic Effects of the Methanol Stem Bark Extract of Brachystegia eurycoma Harms (Fabaceae). Eur. J. Med. Plants, 2: 356-365

Ipshita, C. A.K. and A. Chakravarty, 2006. Daboia russellii and Naja kaouthia venom neutralization by lupeol acetate isolated from the root extract of Indian sarsaparilla Hemidesmus indicus R. Brit. J. Ethnopharmacol., 106: 38-43

Kishimoto, M. and T. Takahashi, 2001. A spectrophotometric microplate assay for L-amino acid oxidase. Anal. Biochem., 298: 136-139

Laemmli, U.K., 1970. Cleavage of structural proteins during the assembly of the head of bacteriophage T4. Nature, 227: 680-685

Mariane, A., C.C. Eduardo and E.B. Sergio, 2011. Cairo PF,Jonathas FRL, Eladio FS. Hypericum basiliense plant extract neutralizes some biological effects of Bothrops jaraca snake venom. J. Ven. Res., 2: $11-16$

Maugini, A., 1930. Some plants of Cyrenaica. Agr. coloniale (Florence), 24: 74-77, 127-131,189-191

McLafferty, F.W., 1989. Registry of Mass Spectral Data, $5^{\text {th }}$ edition. John Wiley and Sons, New York, USA

Mors, W.B., M.C. Nascimento, B.M.R. Pereira and N.A. Pereira, 2000. Plant natural products active against snake bite. the molecular approach. Phytochemistry, 55: 627-642

Mosmann, T., 1983. Rapid colorimetric assay for cellular growth and survival: application to proliferation and cytotoxicity assays. $J$. Immunol. Methods, 65: 55-63
Nishijima, C.M., C.M. Rodrigues, M.A. Silva, M. Lopes-Ferreira, W Vilegas and L.C.A. Hiruma, 2009. Anti-hemorrhagic activity of four Brazilian vegetable species against Bothrops jararaca venom. Molecules, 14: 1072-1080

Otero, R., V. Nunez, S.L. Jimenez, R. Fonnegra, R.G. Osorio, M.E. Garcia and A. Diaz, 2000. Snakebites and ethnobotany in the northwest region of Colombia Part II: Neutralization of lethal and enzymatic effects of Bothrops atrox venom. J. Ethnopharmacol., 71: 505-511

Ouyang, C. and C.M. Teng, 1976. Fibrinogenolytic enzymes of Trimeresurus mucrosquamatus venom. Biochim. Biophys. Acta, 420: 298-308

Pithayanukul, P., J. Leanpolchareanchai, P. Saparpakorn, S. Devaraja, M.S. Kumar and Y.N. Goutham, 2009. Molecular docking studies and anti-snake venom metalloproteinase activity of Thai mango seed kernel extract. Molecules, 14: 3198-3213

Rodrigues, V.M., A.M. Soares, S.R. Guerra, V. Rodrigues, M.R. Fontes and J.R. Giglio, 2000. Structural and functional characterization of neuwiedase, a non-hemorrhagic fibrin(ogen) olytic metalloprotease from Bothrops neuwiedi snake venom. Arch. Biochem. Biophys., 381: $213-224$

Sanchez, E.E. and A. Rodríguez, 2008. Inhibitors of snake venoms and development of new therapeutics. Immunopharmacol. Immunotoxicol., 30: 647-678

Shirwaikar, A., K. Rajendran, R. Bodla and C.D. Kumar, 2004 Neutralization potential of Viper russelli (Russell's viper) venom by ethanol leaf extract of Acalypha indica. J. Ethnopharmacol., 94 267-273

Soares, A.M., A.H. Januario, M.V. Lourenco, A.M.S. Pereira and P.S Pereira, 2004. Neutralizing effects of Brazilian plants against snake venoms. Drugs Fut., 29: 1105

Soares, A.M., F.K. Ticlia, S. Marcussi, M.V. Lourenço, A.H. Januário, S.V. Sampaio, J.R. Giglio, B. Lomonte and P.S. Pereira, 2005. Medicinal Plants with inhibitory properties against snake venoms. Curr. Med. Chem., 12: 2625-2641

Theakston, R.D.G. and H.A. Reid, 1992. Development of simple standard assay procedures for the characterization of snake venom. Bull. World Health Organ. 1983, 61, Martz, W. Plants with a reputation against snakebite. Toxicon, 30: 1131-1142

Ticli, F.K., L.I.S. Hage, R.S. Cambraia, P.S. Pereira, A.J. Magro, M.R.M Fontes, R.G. Stábeli, J.R. Giglio, S.C. França, A.M. Soares and S.V. Sampaio, 2005. Rosmarinic acid, a new snake venom phospholipase A2 inhibitor from Cordia verbenacea (Boraginaceae): Antiserum action potentiation and molecular interaction. Toxicon, 46: 318-327

(Received 20 January 2016; Accepted 15 April 2016) 